\title{
Design and Development of a Reflective Membrane for a Novel Building Integrated Concentrating Photovoltaic (BICPV) 'Smart Window' System
}

\author{
Karen Connelly ${ }^{\mathrm{a}}$, Yupeng $\mathrm{Wu}^{\mathrm{a}, *}, \mathrm{Jun}_{\mathrm{Chen}}^{\mathrm{b}}$ and Yu Lei ${ }^{\mathrm{b}, \mathrm{c}}$

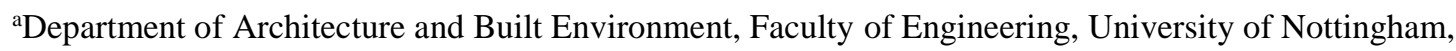 \\ University Park, Nottingham, NG7 2RD, UK \\ bepartment of Biomedical Engineering, University of Connecticut, 260 Glenbrook Road, Unit 3247, Storrs, CT \\ 06269, USA \\ ${ }^{\mathrm{c}}$ Department of Chemical and Biomolecular Engineering, University of Connecticut, 191 Auditorium Road, \\ Unit 3222, Storrs, CT 06269, USA. \\ *Corresponding author: Tel: +44 (0) 11574 84011; emails: Yupeng.Wu@nottingham.ac.uk, Jackwuyp@ googlemail.com
}

\begin{abstract}
:
As a new concept, Building Integrated Concentrating PV (BICPV) "smart window" system consisting of a thermotropic layer with integrated PVs is treated as an electricity-generating smart window or glazed façade. This system automatically responds to climatic conditions by varying the balance of solar energy reflected to the PV for electricity generation and transmitted through the system into the building for provision of light and heat. Its success heavily relies on the understanding of the relationship between the transmittance/reflectance properties and the composition of the thermotropic layer under different environmental temperatures. Herein, hydroxypropyl cellulose (HPC) polymer and gellan gum based hydrogel membranes with different compositions were synthesized as the reflective thermotropic layer for the smart BICPV system and their transmittance and reflectance were systematically investigated in terms of hydrogel composition and environmental temperature. Specifically, a switching temperature $\left(\mathrm{T}_{\mathrm{s}}\right)$ of $\sim 42{ }^{\circ} \mathrm{C}(6 \mathrm{wt}$. \% HPC) was recorded, the measured transmittance decreases from $\sim 90 \%$ to $\sim 20 \%$, with the temperature of the reflective layer increasing from $20^{\circ} \mathrm{C}$ to $60^{\circ} \mathrm{C}$. No hysteresis in optical property was observed upon heating-cooling cycle of HPC membrane samples. The measured reflectivity increased with heating from $\sim 10 \%$ below the $\mathrm{T}_{\mathrm{s}}$ to $\sim 50 \%$ above the $\mathrm{T}_{\mathrm{s}}$ (for $6 \mathrm{wt}$. \% HPC). These features indicate that the as-prepared HPC based thermotropic hydrogel layer holds great potential for application in next generation BICPV smart windows.
\end{abstract}

Key words: Concentrating PV; thermotropic layer; transition temperature; transmittance; reflectivity; hydrogel membrane. 


\section{NOMENCLATURE}

\section{Symbols}

\begin{tabular}{|c|c|c|c|}
\hline D65 & standard illuminant D65 & $-\tau(\lambda)$ & spectral transmittance \\
\hline$\rho(\lambda)$ & spectral reflectance & $-\tau_{v}$ & light transmittance \\
\hline$\rho_{v}$ & light reflectance & $-\tau_{e}$ & solar direct transmittance \\
\hline$\rho_{e}$ & solar direct reflectance & $-D_{\lambda}$ & $\begin{array}{l}\text { relative spectral } \\
\text { distribution of illuminant } \\
\text { D65 }\end{array}$ \\
\hline$V(\lambda)$ & $\begin{array}{l}\text { spectral luminous } \\
\text { efficiency }\end{array}$ & $-S_{\lambda}$ & $\begin{array}{l}\text { relative spectral } \\
\text { distribution of the solar } \\
\text { radiation }\end{array}$ \\
\hline$\lambda$ & wavelength & $-\Delta(\lambda)$ & wavelength interval \\
\hline$T_{s}$ & $\begin{array}{l}\text { threshold switching } \\
\text { temperature }\end{array}$ & & \\
\hline
\end{tabular}

\section{Abbreviations}

\begin{tabular}{|c|c|c|c|}
\hline BICPV & $\begin{array}{l}\text { Building Integrated } \\
\text { Concentrating PV }\end{array}$ & HPC & hydroxypropyl cellulose \\
\hline BIPV & Building Integrated PV & LSC & $\begin{array}{l}\text { Luminescent Solar } \\
\text { Concentrators }\end{array}$ \\
\hline CPV & Concentrating PV & PV & Photovoltaics \\
\hline ESEM & $\begin{array}{l}\text { Environmental Scanning } \\
\text { Electron Microscopy }\end{array}$ & & \\
\hline
\end{tabular}

\section{Introduction}

With more stringent energy reduction targets continually being set by governments and international institutions the necessity to reduce societies carbon footprint continues to increase. [1] The two main strategies for achieving these targets are renewable energy technologies or using energy savings technologies such as via energy efficient building planning. Building Integrated PV system (BIPV) has become a popular way to generate electricity, as it can provide savings in materials and electricity costs, protect building from weather (thermal insulation, shading, etc) and also offer aesthetically pleasing features to the building [2, 3]. When PV or Concentrating PV (CPV) are used for glazing facades or windows, they facilitate penetration of solar radiation through the active areas of the panel directly, or through gaps between opaque solar cells or concentrating units, depending on the types of PV or CPV in use. Besides generating electricity buildings incorporating PV and CPV systems may benefit from the advantage of natural space heating during winter and increased indoor illuminance from daylighting $[4,5]$. In recent years, many theoretical and experimental studies have been conducted to investigate the performance of Building 
Integrated PV and CPV systems. Sadineni et al [6] indicated that the BIPV has a significant contribution to electricity generation in the building and can be used to reduce the peak electricity demand. Yoo and Manz [7], Sun et al. [8] investigated the performance of BIPV designed as window shading device (cladding) to reduce the indoor heat gain in the summer. Wang et al. [9], Chow et al. [10,11], Zogou and Stapountzis [12] studied the performance of BIPV coupled with an air channel, and indicated that such a system has the benefit of increasing the PV performance and also the potential to reduce building cooling loads. Chae et al [27] evaluated the effects of varying electrical and optical parameters of building integrated PV windows with a semi-transparent solar cell on the overall energy performance of typical mid-sized commercial building in various climate conditions. It was indicated that the PV system has the potential to reduce the building output of Carbon by 68.14Tons of Carbon Equivalent per year. Muhammad-Sukki, et al [28, 29] developed a mirror symmetrical dielectric totally internally reflecting concentrator, and investigated its electrical and optical performance for BIPV application. It was predicted that the developed system could achieve a maximum power output of $4.2 \mathrm{x}$ when compared to a similar cell without the concentrator. Abu-Bakar et al [30,31] developed a novel rotationally asymmetrical compound parabolic concentrator with a geometrical concentration ratio of approximately 3.7. A monocrystalline laser grooved buried contact silicon solar cell with dimension of $1 \mathrm{~cm}$ by 1 $\mathrm{cm}$ was integrated with the developed concentrator. A maximum power of $3.3 \mathrm{x}$ was achieved when compared with a counterpart non-concentrating system. Sabry et al [32] designed a low-concentration façade integrated PV system made from transparent acrylic Compound Parabolic Concentrator segments. The proposed system can play an effective role in reducing building cooling loads and also generate electricity. Sabry [33] developed a lowconcentration, PV-coupled prismatic segmented glazing façade that can convert most of the direct solar radiation incident on buildings façades to electricity, while allowing diffuse daylight transmitting to the interior of the building. Kerrouche et al [34] studied the performance of Luminescent Solar Concentrators (LSC) using 3D ray-tracing simulation. The study included 70 samples - both square and circular LSCs, containing five different fluorescent organic dyes each at seven different concentrations. In addition, a comparison between the simulation and experimental measurement were carried out to validate the optical model. Mallick and his group [35-36] designed, developed and experimentally characterised various types of low-concentration PV system that are suitable for building window and façade application. The low concentrating dielectric compound parabolic concentrator system had a maximum power ratio of 2.29 compared to similar flat PV system. 
It also had $2.5 \%$ and $1.6 \%$ higher open circuit voltage and fill factor than the flat plate module. Menoufi et al [37] undertook a life cycle assessment study of a building integrated concentrated PV scheme. The results show the significant extent of the environmental benefits gained using the BICPV schemes. Researches exploring overall energy performance of PV modules were also carried out [13]. Lu and Law [14] found that the BIPV window has the potential to reduce over $65 \%$ of the total heat gain when compared with a conventional clear glass window.

Following on from our previous research on the development of a novel lightweight static Concentrating PV (CPV) system with its performance suitable for use in windows or glazed façades in buildings [15], this paper further develops the aqueous hydroxypropyl cellulose (HPC) thermotropic reflective layer for the proposed CPV system into a membrane that is more appropriate for window application. In addition, the success of the CPV system heavily relies on the understanding of the relationship between the transmittance/reflectance property and the composition of the thermotropic reflective layer under different environmental temperature. Therefore, we have investigated the temperature-dependent transmittance and reflectance effects produced upon 1) systematically changing HPC concentration within the developed gellan gum hydrogel membrane and 2) systematically varying gel concentration.

\section{Methodology}

\subsection{Building Integrated Concentrating PV 'Smart Window' system}

Recently we outlined a Building Integrated Concentrating Photovoltaic (BICPV) 'Smart Window' system concept that could approach challenges in energy efficient buildings from the perspective of both energy efficiency and renewable energy technologies [15]. Firstly the system provides building energy savings via an integrated thermotropic membrane layer and secondly electricity can be generated from reflected incident solar radiation using embedded commercially available photovoltaic (PV) cells. A schematic design of this Concentrating PV (CPV) system is presented in Figure 1. The design is comprised of a glazing cover laminated with a thermotropic layer with solar cells optically coupled around the edges of the glazing. The thermotropic layer varies the proportion of light transmitted through it and scattered from it. A large proportion of any scattered light is directed via total internal reflection towards the edges with optically coupled solar cells. When the temperature of the thermotropic layer is below a designed threshold switching temperature $\left(T_{\mathrm{s}}\right)$ the two main components (e.g. 
polymer and water) are homogeneously mixed, possessing a transparent appearance as shown in Figure 1(b) (preferable transmittance is over $85 \%$ ). Above the threshold $\mathrm{T}_{\mathrm{s}}$, the polymer molecules are aggregated due to thermally-induced phase transition, resulting in a translucent thermotropic layer with diffuse reflectivity. Due to this relatively high diffuse reflectivity the thermotropic layer could scatter most of the sunlight that passes through the front face of the glass with subsequent conversion of scattered lights to electricity by solar cells optically coupled around the edges of the glazing, as displayed in Figure 1(a). This novel CPV can be thought of as an electricity-generating smart window or glazed façade as the system automatically responds to climatic conditions by varying the balance of solar energy reflected to PV cells for electricity generation above the $\mathrm{T}_{\mathrm{s}}$ and solar energy transmitted through the system into the building below the $\mathrm{T}_{\mathrm{s}}$ for provision of light and heat. It therefore offers the potential to optimise energy consumption within buildings. For example, in summer uncomfortably high solar irradiation (which in conventional design is controlled by shading devices and therefore lost to the environment as heat) will be collected by the embedded solar cells resulting in the generation of renewable electricity. In winter, light and heat preferentially pass through the system helping to offset heating and lighting energy demands. When used in a double or triple glazed unit, as shown in Figure 1, the additional panes of glass installed behind the CPV would decouple the concentrator from the indoor thermal environment and therefore prevent any potential unwanted effects that this would create. As solar cells are commercially available at a reasonable price, the major challenge for such CPV system design is the thermotropic layer with a suitable threshold $T_{s}$, which is the focus of this study. It is well-known that the threshold $\mathrm{T}_{\mathrm{s}}$ is highly dependent on the composition of the specific membrane materials. In order to be suitable for window application, the threshold $\mathrm{T}_{\mathrm{s}}$ needs to be linked to the balance temperature of the building (i.e. the temperature at which it switches from a need for heating to a need for cooling). Therefore, the thermotropic layer should have an adjustable $\mathrm{T}_{\mathrm{s}}$ of between $25{ }^{\circ} \mathrm{C}$ to $40{ }^{\circ} \mathrm{C}$ making it adaptable to a range of climatic requirements. For this concept to be successful it is essential that the thermotropic layer is reflective above the $T_{\mathrm{s}}$ and not merely absorbing solar radiation. This reflection has been demonstrated by the use of thermotropic materials for passive overheat protection of solar absorbers whereby if the thermotropic material was absorbing solar radiation, rather than reflecting it, it would not be fulfilling its heating protection requirements. [16] In addition, in the CPV system light with wavelengths of between $350-1100 \mathrm{~nm}$ are required to be scattered in order to be compatible with the spectral response of the solar cells. 
(a) Translucent State (During summer)

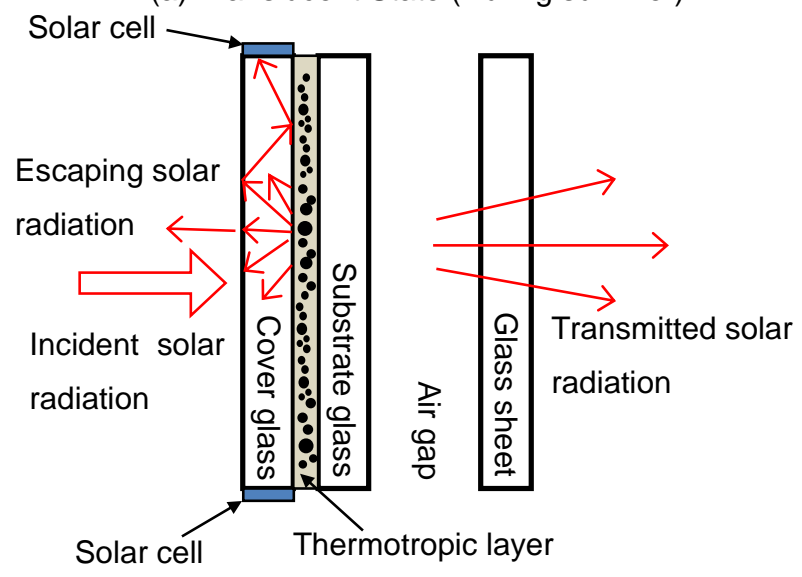

(b) Clear State (During winter)

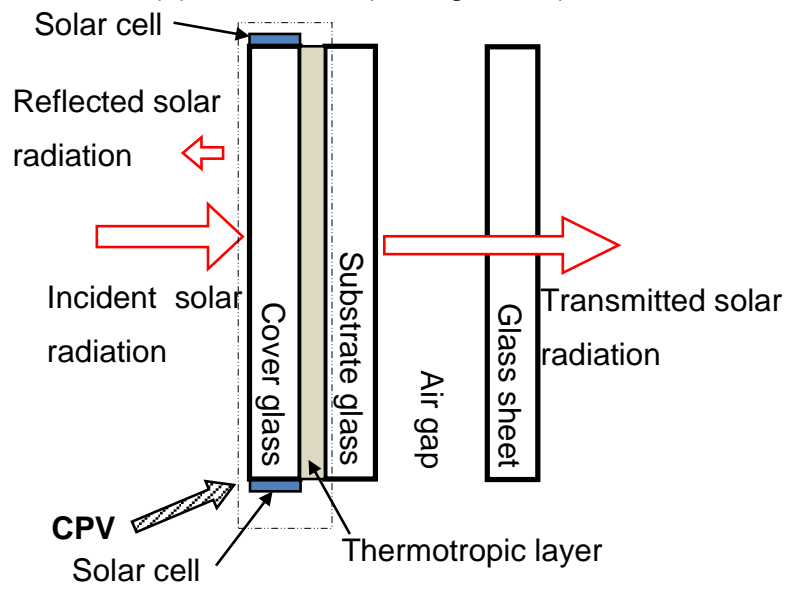

Figure 1. Cross-section view with working principle of the proposed concentrating PV

Stimulated by a literature report in which a cellulose derivative-based hydrogel integrated within the Affinity Intelligent Window (AIW) was composed of $\mathrm{NaCl}$ and two undisclosed materials (cellulose derivative and a non-ionic amphipathic molecule) [17], we demonstrated in our previous work that a hydroxypropyl cellulose (HPC) hydrogel liquid could be synthesized with the required properties for use in the novel CPV concept outlined above [15]. Gellan gum was chosen as the gelling agent used for synthesising the HPC membranes based on the same environmental and safety selection parameters that HPC was chosen. As a fermentation product of bacteria [18], gellan gum is a water-soluble polysaccharide and does not possess thermo-reversibility. Therefore it is well-suited to serve as the matrix for application within smart windows. Dissolved in water above $40^{\circ} \mathrm{C}$ gellan gum adopts a random coil formation which when cooled to room temperature undergoes a transition from disordered-to-ordered forming helices. [19] The gel is produced via association of the helical structures forming junction zones with this helix-coil transition being reversible upon heating. [20] Given the very large number of hydroxyl groups in polysaccharide structures such as HPC and gellan gum it is likely that hydrogen bonding will be predominant in the membrane structure. [21] FTIR studies on bond stretching in HPC-gellan gum blends reported a shift in the O-H stretching peak to a higher wavenumber than observed for HPC or gellan gum alone, indicating that it is intermolecular hydrogen bonding being formed between HPC and gellan gum. [22] Although the $\mathrm{T}_{\mathrm{s}}$ for various compositions of HPC-Gellan-NaCl membranes has been reported in the literature,[23] there is no systematic study on the transmittance/reflectance changes of the thermotropic layer under various compositions and temperature. This is critical for application in the Concentrating Photovoltaic 'Smart Window' System. 


\subsection{Materials and Synthesis}

Hydroxypropyl cellulose (average $M_{w} \sim 80,000$ and average $M_{n} \sim 10,000$ ) was purchased from Sigma Aldrich in the form of an off-white powder. The viscosity range, as reported by the manufacturer, was $150-700 \mathrm{cP}$ for $10 \mathrm{wt}$. $\% \mathrm{HPC}$ in water at $25^{\circ} \mathrm{C}$. The gelling agent used to synthesise HPC into a membrane was received as a white powder. Chemicals were used as received without any further purification. Solutions of varying HPC concentration were prepared as follows. HPC was magnetically stirred into distilled water heated between 50 to $60^{\circ} \mathrm{C}$ for several minutes until all HPC had dissolved. The relevant volume of additional distilled water required to produce the desired HPC wt. \% was then added at room temperature and left stirring for an hour.

To synthesise HPC membranes the relevant amount of gelling powder required to make 0.8 , 1.2 or $1.5 \mathrm{wt}$. \% of the final membrane composition was dissolved into heated distilled water. The required concentration of aqueous HPC to synthesise 2, 4 and 6 wt. \% HPC in the final membrane structure was then added to the heated gel solution whilst stirring. The HPC/gelling agent solution was cast between two $4 \mathrm{~mm}$ thick optical white low iron $5 \times 5 \mathrm{~cm}$ sheets of glazing using a $0.5 \mathrm{~mm}$ silicone membrane between the two glass panes as a spacer, thus resulting in the "truncated" version (no integrated PV) of BICPV smart window.

\subsection{UV-Vis Spectroscopy}

The transmittance and reflection behaviour of membrane samples was measured using an Ocean Optics USB200+ spectrometer. For transmittance measurements a HL-2000 Halogen Light Source was attached to the spectrometer, along with a FOIS-1 integrating sphere with the glazed membrane sample placed directly over the light port for measurement. Throughout this paper the $T_{\mathrm{s}}$ of the membrane sample is quoted as being the temperature at which the thermotropic membrane transmitted $50 \%$ of incoming solar radiation. [24, 25] For reflection measurements an ISP-REF integrating sphere was attached to the USB200+ spectrometer and the glazed membrane sample placed directly over the ISP-REF light port. A WS-1 diffuse reflectance standard was used to measure the reference baseline of $100 \%$ light reflectance. Transmittance and reflection data were collected over a temperature range between $20^{\circ} \mathrm{C}$ to $65^{\circ} \mathrm{C}$ in $5^{\circ} \mathrm{C}$ increments, adjusted to $1^{\circ} \mathrm{C}$ increments within the $\mathrm{T}_{\mathrm{s}}$ range. Each measurement was taken after a 20 minute period to allow for temperature equilibration. Glazing encased membrane samples were heated to within $\pm 1^{\circ} \mathrm{C}$ using a hotplate. After reaching $65^{\circ} \mathrm{C}$ the temperature was reversed to observe any changes in the cooling curve as compared to the 
heating curve. To gain accurate temperature readings throughout experimentation four T-type thermocouples were glued to the upper glazing surface of the membrane samples using highly thermal-conducting Electrolube Thermal Bonding System. The temperature recorded from these four thermocouples was then averaged. Prior to transmittance or reflectance testing a single $4 \mathrm{~mm}$ thick optical white low iron sheet of glazing was used to gain a reference baseline standard. Experiments were repeated in at least triplicate in order to validate the accuracy of results.

\subsection{Environmental Scanning Electron Microscopy (ESEM)}

A Philips XL30 FEG ESEM was used to characterize the surfaces of the hydrogel membranes without removing water from the membrane structure. The XL30 FEG ESEM is a modern PC controlled instrument. It has the performance of a conventional SEM, but has the advantage of being able to examine practically any material in its natural state in a gaseous environment at pressures as high as $1330 \mathrm{~Pa}$ (10 torr) and temperatures as high as $1500^{\circ} \mathrm{C}$. Due to the multiple pressure limiting apertures (PLA) and its environmental secondary electron detectors (GSED), the microscope can offer high-resolution images in a saturated water vapour environment keeping the sample in its original wet state (minimum 4.6 Torr at $0^{\circ} \mathrm{C}$ ). When testing the developed membrane samples, they were held at $4^{\circ} \mathrm{C}$ in order to keep the sample hydrated at chamber pressures of 3.2 to 4.5 Torr. An acceleration voltage of $10 \mathrm{kV}$ was used with a working distance of $10 \mathrm{~mm}$.

\section{Results and Discussion}

ESEM photographs were taken of the surface of a $6 \mathrm{wt}$ \% HPC membrane samples with different concentration of gelling agent in the membrane structure. The temperature of the chamber was maintained at $4^{\circ} \mathrm{C}$ so as to keep the membrane samples hydrated therefore membranes were photographed in the transparent state well below the $\mathrm{T}_{\mathrm{s}}$. Photographs could not be taken of samples above the $\mathrm{T}_{\mathrm{s}}$ due to challenges keeping a 'wet' atmosphere within the chamber and therefore keeping samples hydrated at these temperatures. Figure 2 shows the surface of a 6 wt. \% HPC membrane sample synthesised using 0.8 wt. \% (left) and 1.5 wt. \% (right) gelling agent, respectively. As shown, the hydrogel membrane surface is smooth and homogeneous resulting in uniform light transmittance and reflectance, which is critical for use as a thermotropic layer within glazing. 
Figure 2. ESEM photographs of $6 \mathrm{wt}$ \% HPC hydrogel membrane synthesised with $0.8 \mathrm{wt}$ \% $\%$ gelling agent (left) and $1.5 \mathrm{wt}$. $\%$ gelling agent (right), respectively.

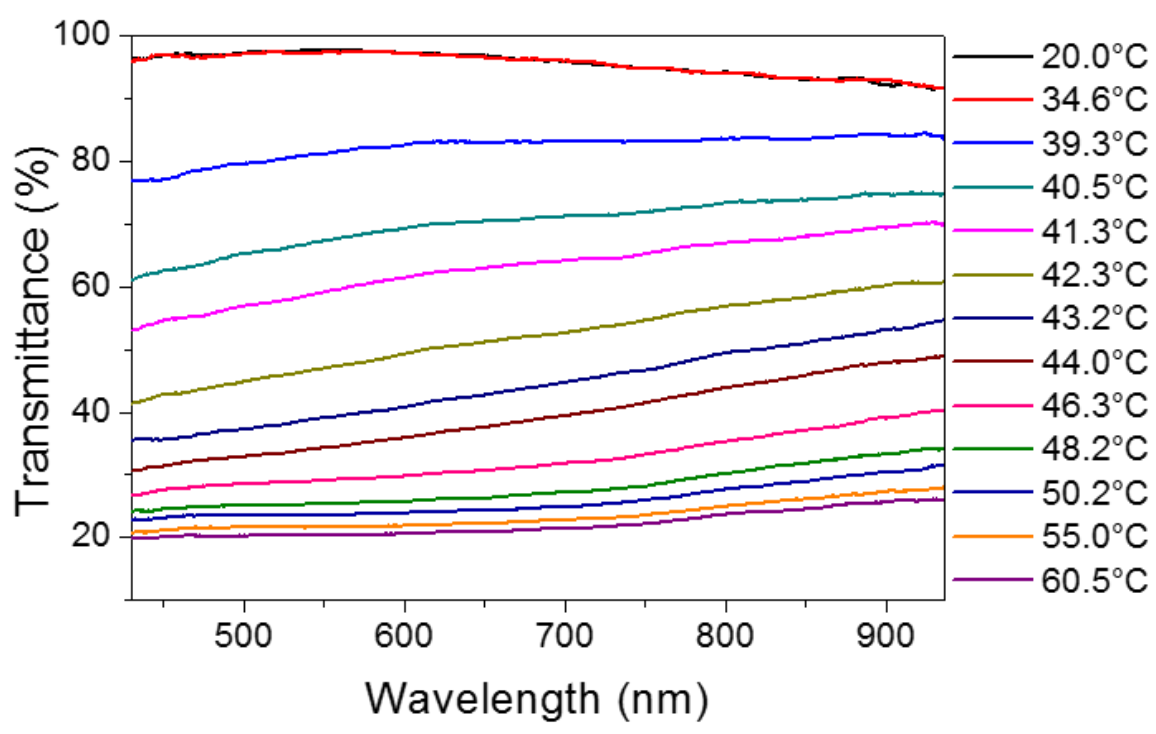

Figure 3. UV-Vis spectra over the temperature range $20-60.5^{\circ} \mathrm{C}$ showing transmittance of 6 wt. $\%$ HPC within a 1.5 wt. \% gelling agent membrane.

Membranes were synthesized using 2, 4 and 6 wt. \% HPC to compare changes to light transmittance and reflectivity due to the addition of the gelling agent to HPC. Figure 3 is a UV-vis spectrum of a typical HPC hydrogel membrane sample synthesised with 1.5 wt. \% gelling agent showing $>90 \%$ transmittance below the $\mathrm{T}_{\mathrm{s}}$ and low transmittance of $\sim 20-25$ $\%$ above the $\mathrm{T}_{\mathrm{s}}$. With increased temperature the amount of visible light transmitted decreased more rapidly than the amount of near infra-red light. 
The photographs in Figure 4 of the glazing encased 6 wt. \% HPC, 1.5 wt. \% gelling agent membrane sample show that below the $T_{s}$ optical transparency is suitable for glazing purposes and that the thermotropic effect of the HPC within the membrane is still functional above the $\mathrm{T}_{\mathrm{s}}$.

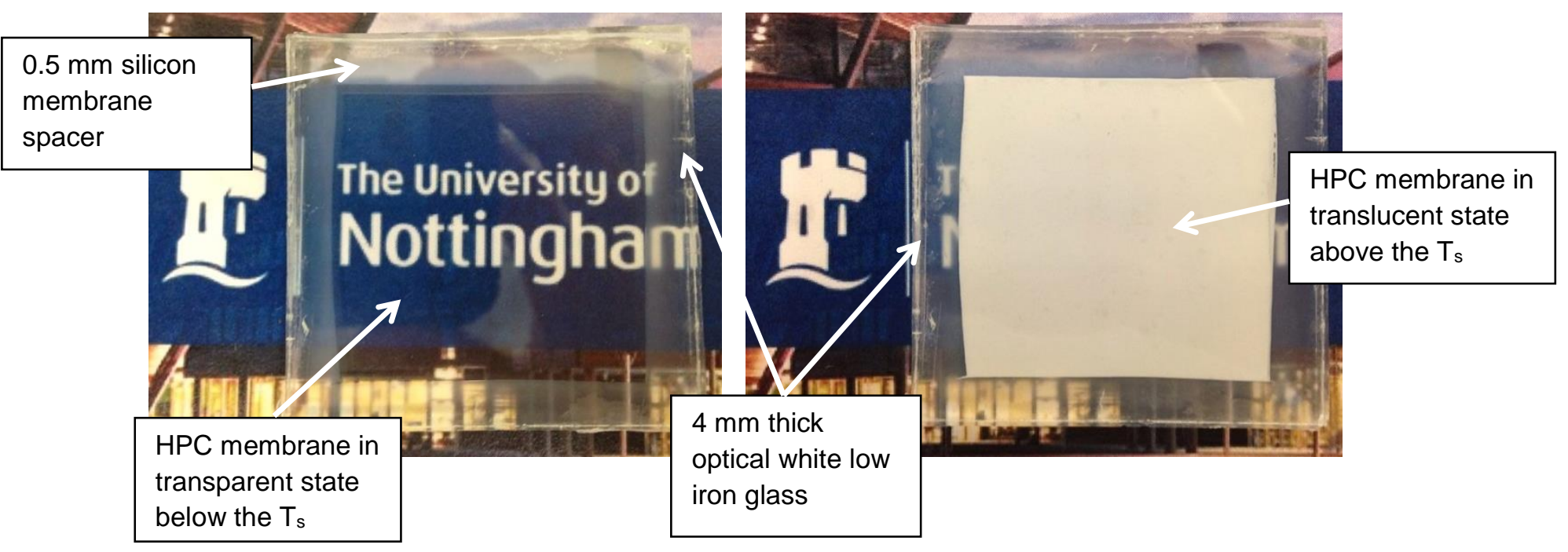

Figure 4. Photograph of $6 \mathrm{wt}$. \% HPC, $1.5 \%$ gelling agent hydrogel membrane below the $\mathrm{T}_{\mathrm{s}}$ at room temperature (left photograph) and heated above the $T_{s}$ (right photograph).

Figure 5 shows the transmittance behaviour of HPC membrane samples when exposed to increased temperature. When compared to our previous research on aqueous HPC solutions, as shown in Figure 6, one can seen that increased HPC concentration results in a decrease in $\mathrm{T}_{\mathrm{s}}$ for both aqueous and membrane HPC samples. Specifically, Figure 5 shows that the $2 \mathrm{wt}$. $\%$ HPC, 1.5 wt. $\%$ gelling agent membrane sample has a $\mathrm{T}_{\mathrm{s}}$ of $\sim 45^{\circ} \mathrm{C}$ whilst the 6 wt. \% HPC, 1.5 wt. $\%$ gelling agent membrane sample has a $\mathrm{T}_{\mathrm{s}}$ of $\sim 42^{\circ} \mathrm{C}$. This is an increase of $\sim 2$ ${ }^{\circ} \mathrm{C}$ as compared to the $\mathrm{T}_{\mathrm{s}}$ 's measured for aqueous HPC samples as shown in Figure 6 and is likely attributed to the increased strength of the intermolecular hydrogen bonding formed between HPC and gellan gum as compared to the hydrogen bonding between water and HPC. Light transmittance below the $\mathrm{T}_{\mathrm{s}}$ is similar to that observed for aqueous HPC solutions whilst above the $\mathrm{T}_{\mathrm{s}}$ transmittance varies between $220 \%$ for $6 \mathrm{wt}$. $\%$ HPC to $\sim 30 \%$ for $2 \mathrm{wt}$. $\%$ HPC, as compared to $\sim 0$ transmittance for aqueous HPC samples. This is reasonably ascribed to the long light path length through aqueous HPC samples being $10 \mathrm{~mm}$ as compared to membrane thickness being $0.5 \mathrm{~mm}$. Increasing HPC concentration in membrane samples was expected to lower the $\mathrm{T}_{\mathrm{s}}$ value since inter- and intrachain hydrophobicity drive HPC chain aggregation at elevated temperature, therefore the greater amount of HPC chains present in a sample the less energy required to dehydrate HPC resulting in translucence. The 
decrease in transmittance observed above the $\mathrm{T}_{\mathrm{s}}$ from $\sim 30 \%$ for $2 \mathrm{wt} . \% \mathrm{HPC}$ to $\sim 20 \%$ for 6 wt. \% HPC is again an effect of the increased HPC concentration causing increased HPC inter- and intrachain hydrophobicity resulting in a decrease in the observed light transmittance above the $\mathrm{T}_{\mathrm{s}}$ with increased HPC concentration.

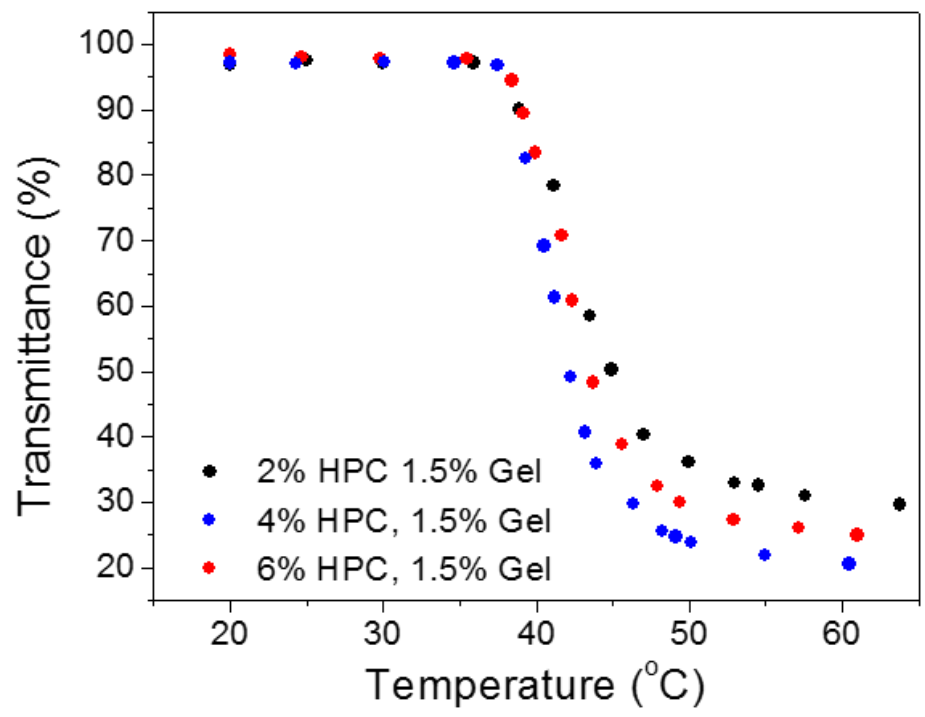

Figure 5. UV-Vis spectra of 2, 4 and $6 \mathrm{wt}$. \% HPC within a $1.5 \mathrm{wt}$ \% gelling agent membrane showing transmittance change at $600 \mathrm{~nm}$ with increased temperature.

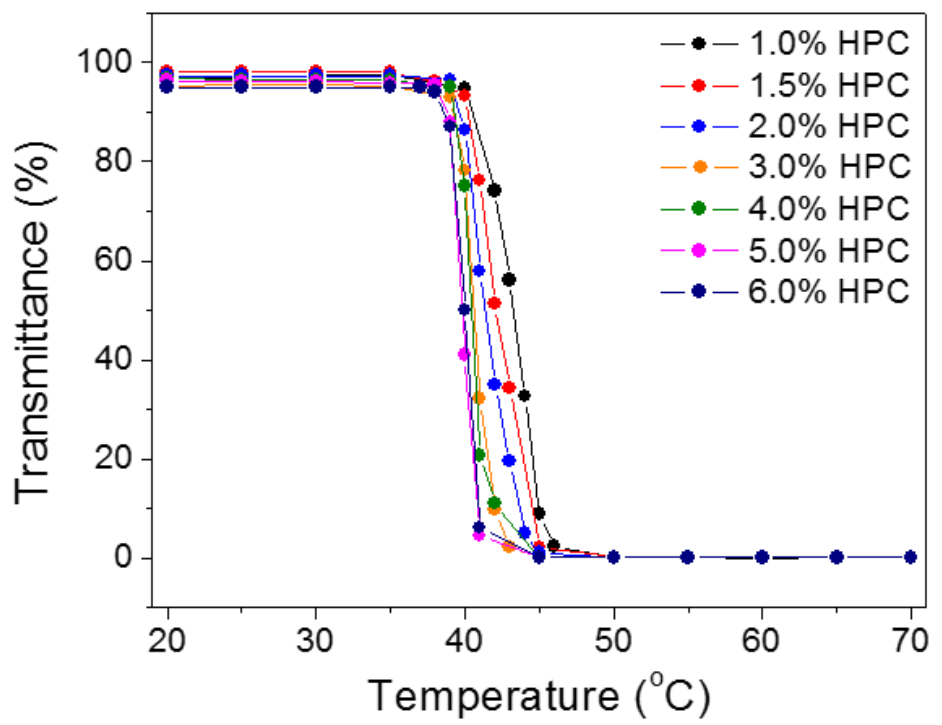

Figure 6. UV-Vis spectra at $600 \mathrm{~nm}$ of various wt. \%'s of HPC in aqueous solution showing transmittance change with increased temperature.

The methods outlined in BSI Standards BS EN 410:2011 [26] were used to calculate average visible light transmittance in the wavelength range $430 \mathrm{~nm}-780 \mathrm{~nm}$ (Eq. 1) and direct solar transmittance in the range $440 \mathrm{~nm}-950 \mathrm{~nm}$ (Eq. 2): 


$$
\begin{gathered}
\tau_{v}=\frac{\sum_{\lambda=380 \mathrm{~nm}}^{780 \mathrm{~nm}} D_{\lambda} \tau(\lambda) V(\lambda) \Delta \lambda}{\sum_{\lambda=380 \mathrm{~nm}}^{780 \mathrm{~nm}} D_{\lambda} V(\lambda) \Delta \lambda} \\
\tau_{e}=\frac{\sum_{\lambda=300 \mathrm{~nm}}^{2500 \mathrm{~nm}} S_{\lambda} \tau(\lambda) \Delta \lambda}{\sum_{\lambda=300 \mathrm{~nm}}^{2500 \mathrm{~nm}} S_{\lambda} \Delta \lambda}
\end{gathered}
$$

$\tau_{v}$ is the visible light transmittance.

$D_{\lambda}$ is the relative spectral distribution of illuminant D65.

$\tau(\lambda)$ is the spectral transmittance of the glazing.

$V(\lambda)$ is the spectral luminous efficiency for photopic vision defining the standard observer for photometry.

$\Delta \lambda$ is the wavelength interval.

$\tau_{e}$ is the solar direct transmittance.

$S_{\lambda}$ is the relative spectral distribution of the solar radiation.

Figure 7 shows the averaged transmittance data at different temperatures using Eq. 1 (labelled as Vis Light T \%) and Eq. 2 (labelled as Direct Solar T \%) for both the lowest (2 wt. \%) and highest (6 wt. \%) concentration HPC membranes tested. Comparing the data for Vis Light T $\%, 600 \mathrm{~nm} \mathrm{~T} \mathrm{\%} \mathrm{and} \mathrm{Direct} \mathrm{Solar} \mathrm{T} \mathrm{\%} \mathrm{for} \mathrm{either} \mathrm{sample} \mathrm{shows} \mathrm{that} \mathrm{there} \mathrm{is} \mathrm{very} \mathrm{little}$ difference in transmittance values both below and above the $T_{s}$, as well as for the $T_{s}$ range, therefore the $600 \mathrm{~nm}$ transmittance values give reliable transmittance data for further analysis.

Light transmittance data for HPC membrane samples was also recorded upon heating up to $65^{\circ} \mathrm{C}$, and then upon cooling back down from $65^{\circ} \mathrm{C}$ to $20^{\circ} \mathrm{C}$. Figure 8 shows both the heating and cooling data for $2 \mathrm{wt} \%$ and $6 \mathrm{wt}$ \% HPC, $1.5 \mathrm{wt}$ \% gelling agent membrane samples. For each hydrogel membrane, the temperature-dependent light transmittance curves upon heating almost overlays with the corresponding curve upon cooling. This data fully corroborates that prior heating of the sample does not affect the light transmittance properties when the sample is cooled back down again, indicating no hysteresis and good reversibility. This is a promising attribute for potential use within a thermotropic smart window. 


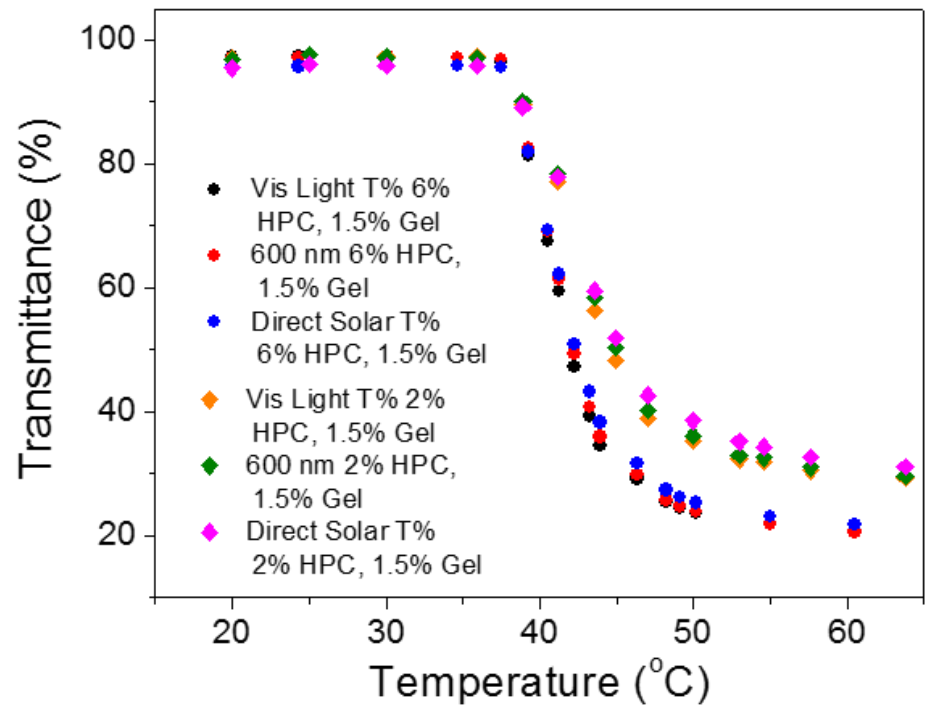

Figure 7. UV-Vis of 2 and $6 \mathrm{wt}$ \% HPC within a $1.5 \mathrm{wt}$ \% gelling agent membrane showing transmittance change with increased temperature at $600 \mathrm{~nm}$, averaged over $430 \mathrm{~nm}$ to $780 \mathrm{~nm}$ (Vis Light T\%) and averaged over $440 \mathrm{~nm}$ to $950 \mathrm{~nm}$ (Direct Solar T\%).

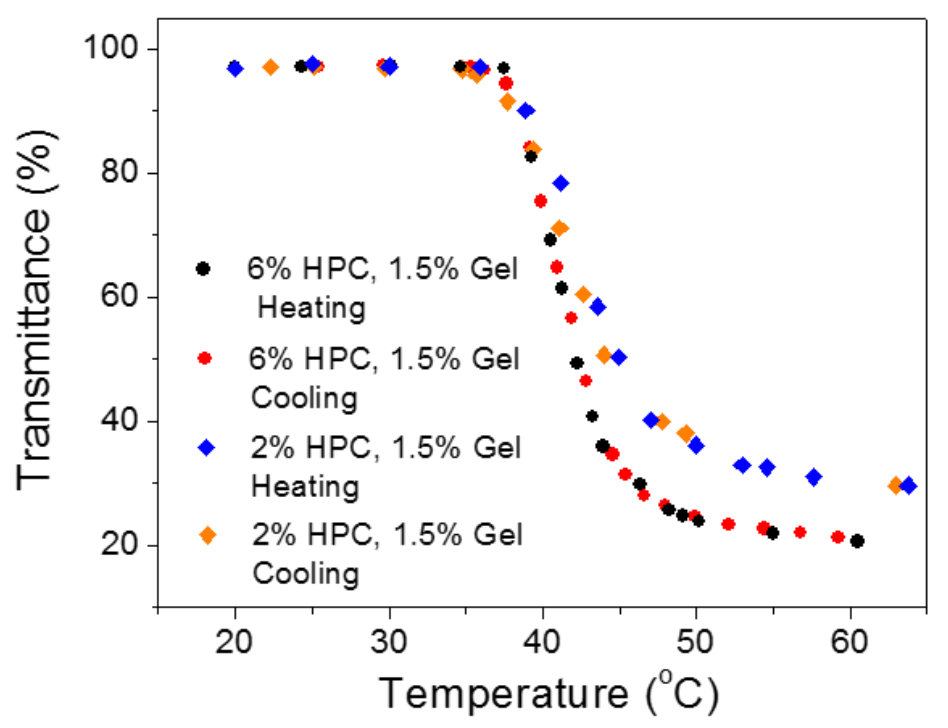

Figure 8. UV-Vis spectra at $600 \mathrm{~nm}$ of 2 wt. \% and $6 \mathrm{wt}$. \% HPC within a $1.5 \mathrm{wt}$. \% gelling agent membrane showing transmittance change with increased temperature (heating) and subsequent reduction in temperature (cooling).

Reflectance of HPC membrane samples between $20-65^{\circ} \mathrm{C}$ was also measured both below and above the $\mathrm{T}_{\mathrm{s}}$. Figure 9 is a typical UV-vis spectra showing reflectance with increased temperature of the 6 wt. \% HPC, 1.5 wt. \% gelling agent membrane. The results show that prior to heating HPC membrane samples have $\sim 10 \%$ reflectance below the $\mathrm{T}_{\mathrm{s}}$. A greater amount of reflection was observed within the visible light region than within the near infrared region as the temperature was increased up to a maximum of $60^{\circ} \mathrm{C}$. 
Above the $T_{s}$ the reflectivity of membrane samples increased with increased HPC concentration as shown in Figure 10, inverse to the observed decrease in light transmittance above the $\mathrm{T}_{\mathrm{s}}$ with increased HPC concentration as shown in Figure 5. The 6 wt. \% HPC, 1.5 wt. \% gelling agent membrane sample showed that the greatest reflectivity observed above the $\mathrm{T}_{\mathrm{s}}$ was at $\sim 4 \%$. The increase in reflectivity with increased HPC concentration is expected to continue using higher HPC concentrations on the basis that the greater the concentration of HPC within the membrane structure, the greater the amount of HPC aggregation, and therefore the greater the opportunity for light to be reflected.

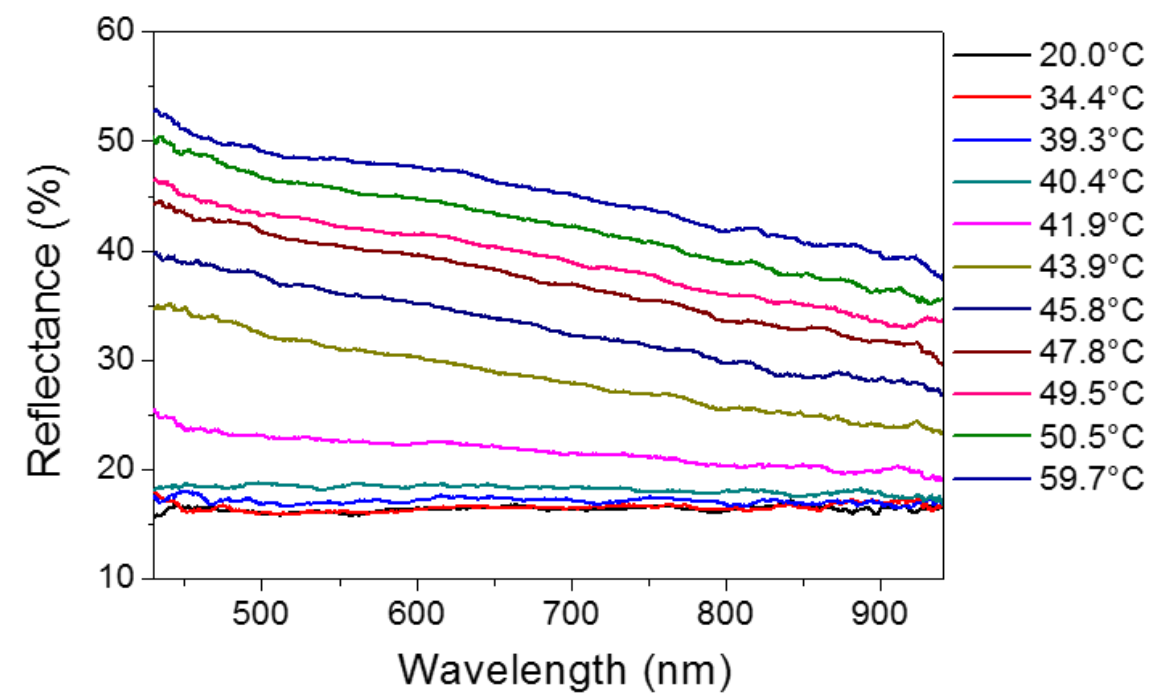

Figure 9. UV-Vis spectra over the temperature range of $20-60{ }^{\circ} \mathrm{C}$ showing reflectance change of 6 wt. $\%$ HPC within a 1.5 wt. \% gelling agent membrane

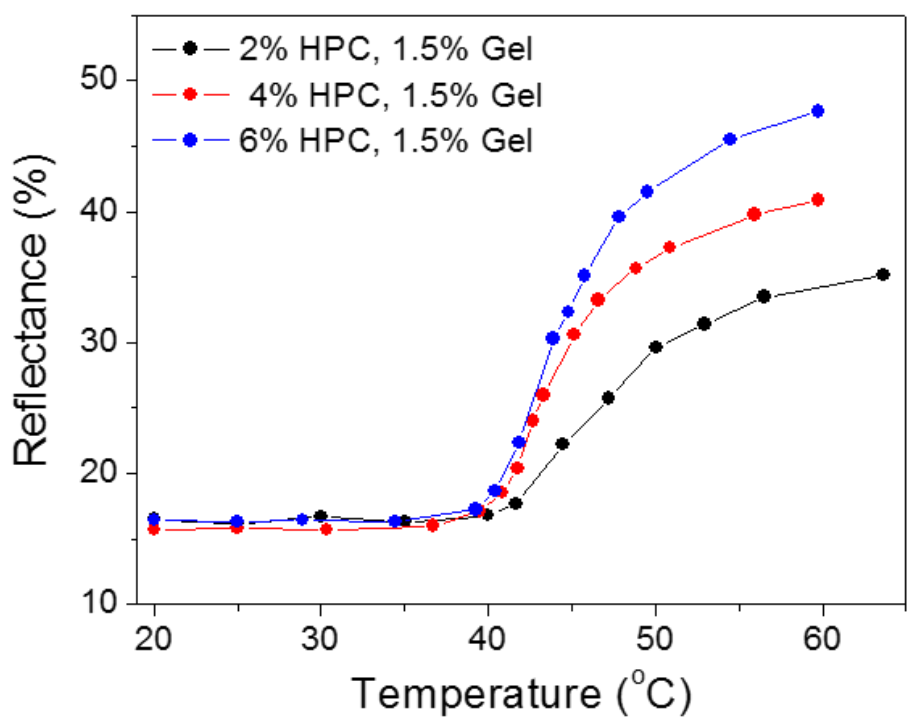

Figure 10. UV-Vis spectra at $600 \mathrm{~nm}$ of 2,4 and $6 \mathrm{wt}$. \% HPC within a $1.5 \mathrm{wt}$. \% gelling agent membrane showing reflectance change with increased temperature. 
The methods outlined in BSI Standards BS EN 410:2011 [26] were again used to calculate the average visible light reflectance from $430 \mathrm{~nm}-780 \mathrm{~nm}$ and the direct solar reflectance from $440 \mathrm{~nm}-950 \mathrm{~nm}$ using Eq. 3 and Eq. 4 respectively.

$$
\begin{gathered}
\rho_{v}=\frac{\sum_{\lambda=380 \mathrm{~nm}}^{780 \mathrm{~nm}} D_{\lambda} \rho(\lambda) V(\lambda) \Delta \lambda}{\sum_{\lambda=380 \mathrm{~nm}}^{780 \mathrm{~nm}} D_{\lambda} V(\lambda) \Delta \lambda} \\
\rho_{e}=\frac{\sum_{\lambda=300 \mathrm{~nm}}^{2500 \mathrm{~nm}} S_{\lambda} \rho(\lambda) \Delta \lambda}{\sum_{\lambda=300 \mathrm{~nm}}^{2500 \mathrm{~nm}} S_{\lambda} \Delta \lambda}
\end{gathered}
$$

$\rho_{v}$ is the visible light reflectance.

$D_{\lambda}$ is the relative spectral distribution of illuminant D65.

$\rho(\lambda)$ is the spectral reflectance of the glazing.

$V(\lambda)$ is the spectral luminous efficiency for photopic vision defining the standard observer for photometry.

$\Delta \lambda$ is the wavelength interval.

$\rho_{e}$ is the solar direct reflectance.

$S_{\lambda}$ is the relative spectral distribution of the solar radiation.

The reflectance data averaged for both 2 wt. $\%$ and 6 wt. $\%$ HPC, 1.5 wt. $\%$ gelling agent membrane samples are shown in Figure 11. This figure reaffirms that above the $\mathrm{T}_{\mathrm{s}}$ there is a larger proportion of light in the visible light wavelength region being reflected than light in the $780 \mathrm{~nm}$ to $950 \mathrm{~nm}$ wavelength range, as already observed in Figure 9. 


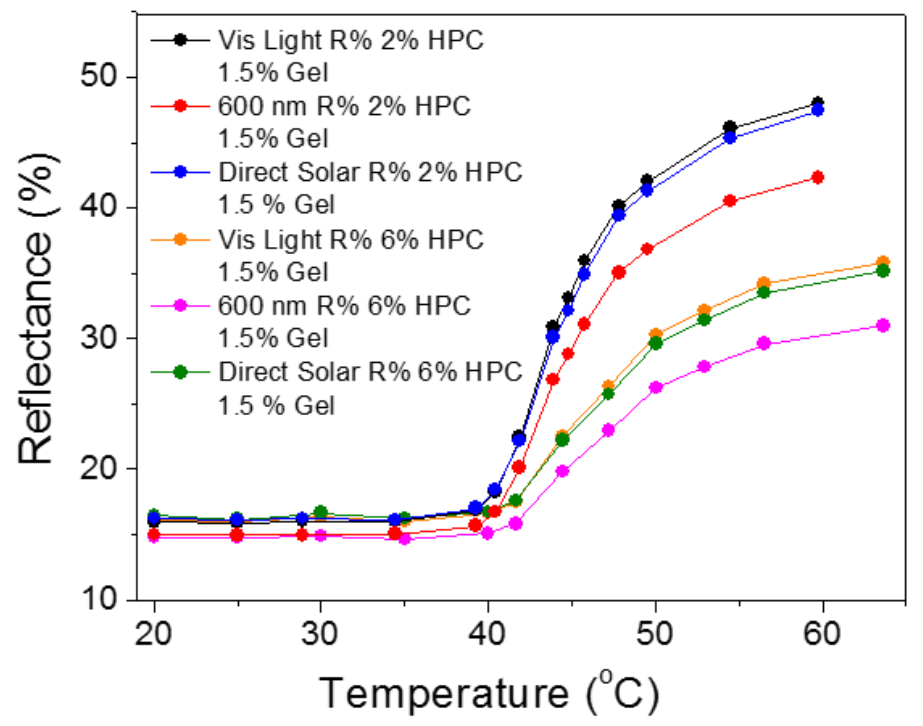

Figure 11. UV-Vis spectra of 2 and 6 wt. \% of HPC within a $1.5 \mathrm{wt}$ \% gelling agent membrane showing reflectance change with increased temperature at $600 \mathrm{~nm}$, averaged over $430 \mathrm{~nm}$ to $780 \mathrm{~nm}$ (Vis Light T\%) and averaged over $440 \mathrm{~nm}$ to $950 \mathrm{~nm}$ (Direct Solar T\%).

Reflectance data of the membrane samples was also recorded after heating the samples up to $65{ }^{\circ} \mathrm{C}$ and then allowing the samples to cool down to $20^{\circ} \mathrm{C}$ as shown for $2 \mathrm{wt}$. $\%$ and 6 wt. $\%$ HPC, 1.5 wt. \% gel membrane samples in Figure 12. From this data it can be seen that prior heating of the sample has no effect on the light reflectance properties of the membrane when the sample is cooled back down again, in good agreement with the conclusion drawn from transmittance data in Figure 8.

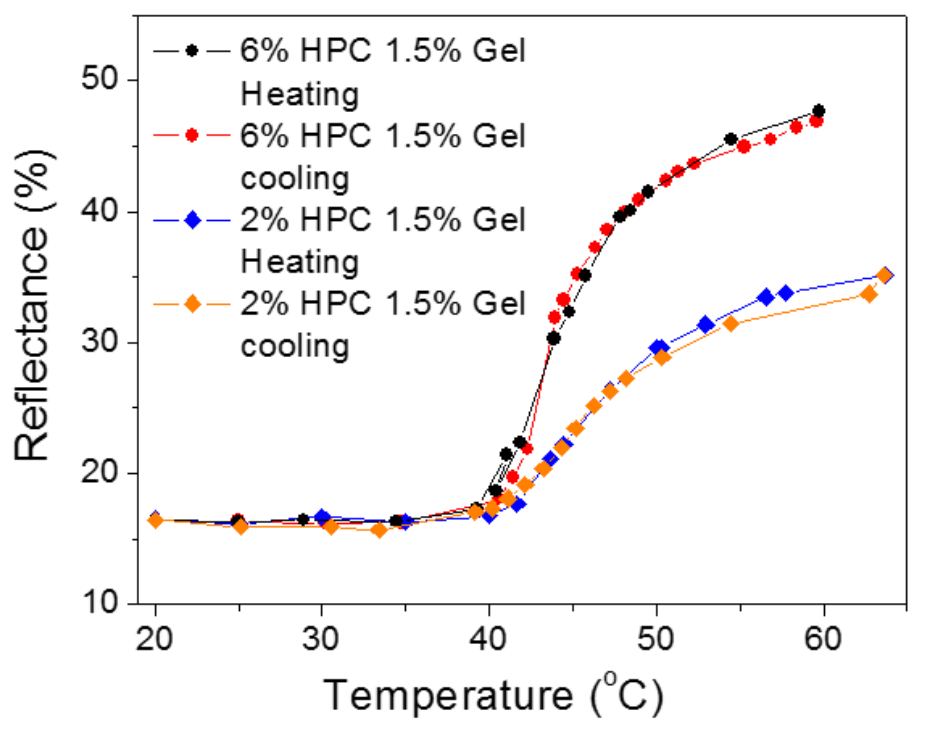

Figure 12. UV-Vis spectra at $600 \mathrm{~nm}$ for $2 \mathrm{wt}$. \% and $6 \mathrm{wt}$. \% HPC within a $1.5 \mathrm{wt}$. \% gelling agent membrane showing reflectivity with increased temperature (heating) and subsequent reduction in temperature (cooling). 


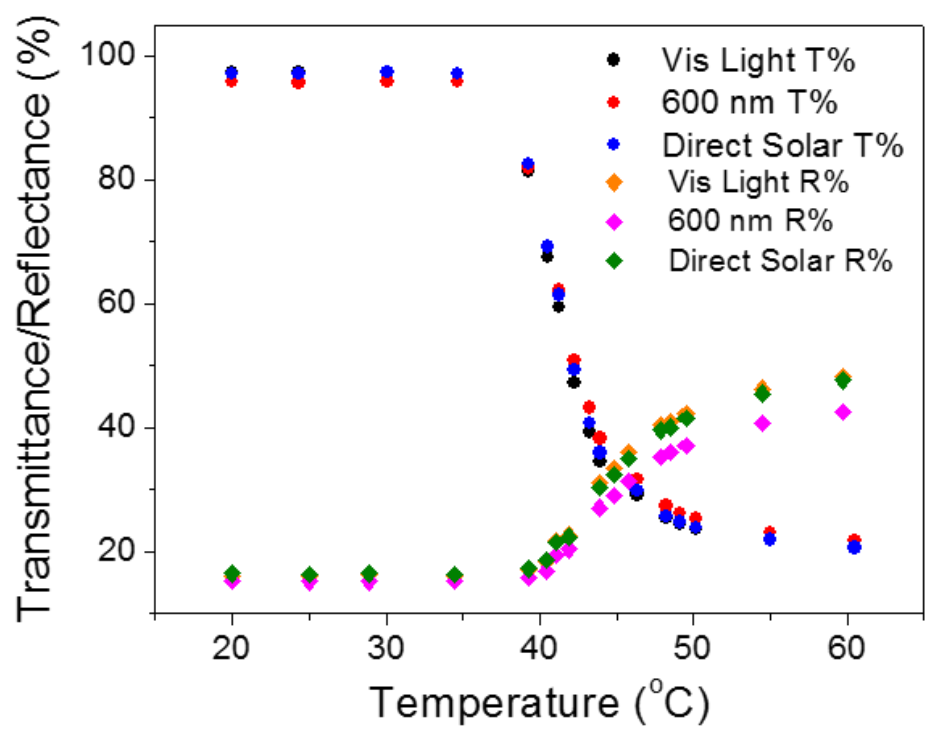

Figure 13. UV-Vis spectra for $6 \mathrm{wt}$ \% HPC within a $1.5 \mathrm{wt}$ \% $\%$ gelling agent membrane showing transmittance and reflectance change with increased temperature at $600 \mathrm{~nm}$, averaged over $430 \mathrm{~nm}$ to $780 \mathrm{~nm}$ (Vis Light T\%) and averaged over $440 \mathrm{~nm}$ to $950 \mathrm{~nm}$ (Direct Solar T\%).

Figure 13 shows both transmittance and reflectance data for 6 wt. \% HPC, 1.5 wt. \% gelling agent membrane sample. The data for both transmittance and reflectance below the $\mathrm{T}_{\mathrm{S}}$ do not total $100 \%$ due to different baselines being applied. The transmittance and reflectance of the system were relevant to a $4 \mathrm{~mm}$ thick low iron glazing, i.e. the measured transmittance of the system was higher than that when compared to air. From Figure 13 it can be concluded that transmittance starts to decrease and reflectance increase at $\sim 40^{\circ} \mathrm{C}$ with both reflectance and transmittance levelling off by $\sim 60^{\circ} \mathrm{C}$. The increase in reflectivity from $\sim 10 \%$ below the $\mathrm{T}_{\mathrm{s}}$ to $\sim 47 \%$ above the $\mathrm{T}_{\mathrm{s}}$ for the visible light average is not as significant as the decrease in light transmittance from $\sim 97 \%$ below the $\mathrm{T}_{\mathrm{s}}$ decreasing to $\sim 20 \%$ above the $\mathrm{T}_{\mathrm{s}}$ for the visible light average.

Finally, the effect of gelling agent concentration on the optical property of the as-prepared membrane samples was also investigated. The wt. \% of gelling agent used in the membrane samples was varied using 0.8 and 1.2 wt. \% gelling agent, to compare against 1.5 wt. \% gelling agent, and then tested for light transmittance and reflectance behaviour over the temperature range of $20{ }^{\circ} \mathrm{C}$ to $60{ }^{\circ} \mathrm{C} .6 \mathrm{wt}$. \% HPC was chosen as the HPC concentration in the membrane samples due to the $6 \mathrm{wt}$. \% HPC concentration exhibiting the lowest $\mathrm{T}_{\mathrm{s}}$ and highest reflectivity above the $\mathrm{T}_{\mathrm{s}}$ among all HPC concentrations tested. It can be seen from Figure 14 that transmittance below the $T_{s}$ is unaffected by increasing the wt. \% of gelling agent, whilst the $\mathrm{T}_{\mathrm{s}}$ and light transmittance above the $\mathrm{T}_{\mathrm{s}}$ are lowered upon increasing the wt. 
$\%$ of gelling agent up to $1.5 \mathrm{wt}$. \%. This reduction of $\mathrm{T}_{\mathrm{s}}$ and transmittance above the $\mathrm{T}_{\mathrm{s}}$ with increased wt. $\%$ of gelling agent follows the same trend as observed for increasing the wt. \% of HPC in the membrane sample as shown in Figure 5.

The reflectivity data in Figure 14 suggests that the 1.5 wt. \% gelling agent membrane, which had the lowest transmittance above the $\mathrm{T}_{\mathrm{s}}$, inversely has the highest reflectivity above the $\mathrm{T}_{\mathrm{s}}$ with $\sim 47 \%$ reflectance at $60^{\circ} \mathrm{C}$. Reflectivity below the $\mathrm{T}_{\mathrm{s}}$ was observed to be unaffected by increasing the wt. $\%$ of gelling agent used. The increase in the measured reflectivity of the membrane sample with increased wt. \% of gelling agent follows the same trend as observed for increasing HPC wt. \% as shown in Figure 10.

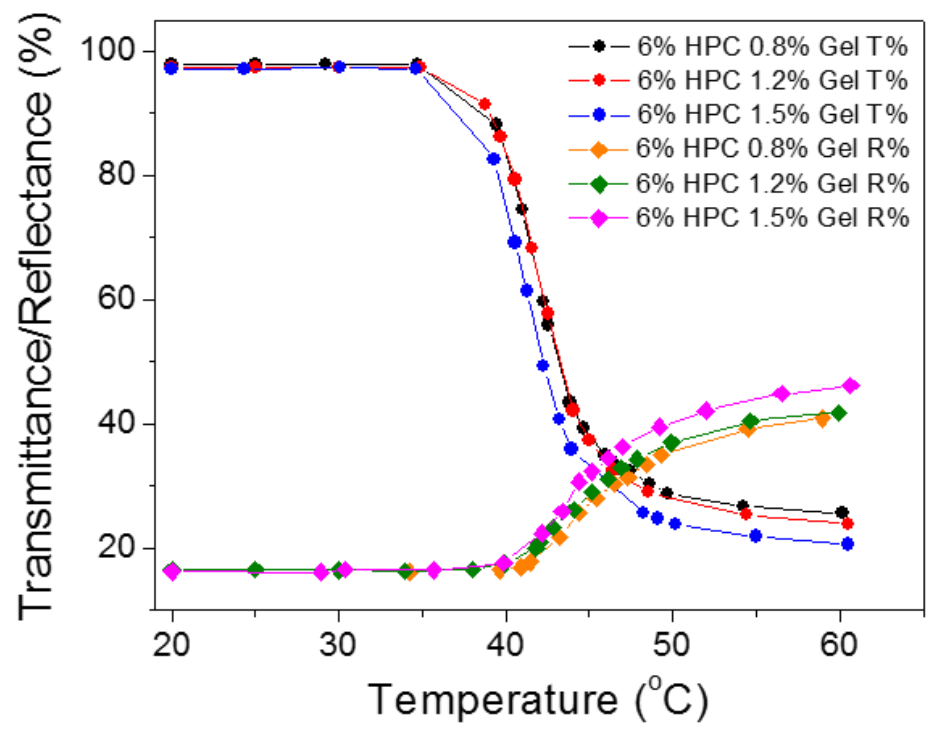

Figure 14. UV-Vis spectra at $600 \mathrm{~nm}$ for $6 \mathrm{wt}$ \% HPC within a $0.8,1.2$ and $1.5 \mathrm{wt}$. \% gelling agent membrane showing transmittance and reflectance with increased temperature.

\section{Conclusion}

In this study, the transmittance and reflectance of thermotropic membranes synthesised using HPC and gellan gum were systematically investigated in terms of hydrogel composition and temperature. The results show that HPC-gellan gum membrane samples possess $>90 \%$ transmittance below the $\mathrm{T}_{\mathrm{s}}$, and are therefore optically transparent, while are observed to be optically opaque above the $\mathrm{T}_{\mathrm{s}}$. The highest performing membrane sample at $6 \mathrm{wt}$. \% HPC, 1.5 wt. gelling agent had a $\mathrm{T}_{\mathrm{s}}$ of $42^{\circ} \mathrm{C}$ and a reflectance above the $\mathrm{T}_{\mathrm{s}}$ of $\sim 47 \%$. The transmittance and reflectance data collected for the membrane samples were consistent upon heating samples from $20^{\circ} \mathrm{C}$ to $65{ }^{\circ} \mathrm{C}$ and then cooling back down to $20{ }^{\circ} \mathrm{C}$. Therefore there is no dependency of either the light transmittance or light reflectance upon whether the HPC 
hydrogel membrane in a "truncated" version (no integrated PV) of BICPV smart window system was being heated up or cooled down, which is critical for any real application. This study provides a clear picture on the relationship among the transmittance/reflectance property, the composition of the HPC hydrogel membrane, and environmental temperature, which paves the road for its application in next generation BICPV smart window design. This novel BICPV smart window can be thought of as an electricity-generating smart window or glazed façade as the system automatically responds to climatic conditions (solar radiation and ambient temperature) by varying the balance of solar energy reflected to PV cells for electricity generation above the $\mathrm{T}_{\mathrm{s}}$ and solar energy transmitted through the system into the building below the $\mathrm{T}_{\mathrm{s}}$ for provision of light and heat. It therefore offers the potential to optimise energy consumption (cooling, heating and lighting) within buildings and also for electricity generation.

\section{Acknowlegment}

This work is supported by Faculty of Engineering University of Nottingham through the Dean of Engineering Prize.

\section{References}

1. International Energy Agency, World Energy Outlook 2012. http://www.iea.org/publications/freepublications/publication/WEO2012_free.pdf, 2012.

2. Taehoon Hong, Choongwan Koob, Jeongyoon Oh, Kwangbok Jeong, Nonlinearity analysis of the shading effect on the technical-economic performance of the buildingintegrated photovoltaic blind, Applied Energy, doi:10.1016/j.apenergy.2016.05.027.

3. M. Sabry, P.C. Eames, H. Singh, Y. Wu, Smart windows: Thermal modelling and evaluation, Solar Energy, 2014, 103, 200-209

4. Wong, P.W., Shimoda, Y., Nonaka, M., Inoue, M. and Mizuno, M. Semi-transparent PV: Thermal performance, power generation, daylight modelling and energy saving potential in a residential application. Renewable Energy, 2008, 33, 1024-1036.

5. Daniel Chemisana, Victoria Collados, Manuel Quintanilla, Jesús Atencia, Holographic lenses for building integrated concentrating photovoltaics, Applied Energy, 2013, 110, 227-235.

6. Suresh B. Sadineni, Fady Atallah and Robert F. Boehm, Impact of roof integrated PV orientation on the residential electricity peak demand, Applied Energy, 2012, 92, 204210.

7. Yoo, S. H. and Manz, H., Available remodelling simulation for a BIPV as a shading device. Solar Energy Materials \& Solar Cells, 2011, 95, 394-397.

8. Sun Liangliang, Lu Lin and Yang Hongxing, Optimum design of shading-type building - integrated photovoltaic claddings with different surface azimuth angles, Applied Energy, 2012, 90, 233-240. 
9. Wang Y.P., Tian W., Ren J.B., Zhu L. and Wang Q.Z. Influence of a building's integrated-photovoltaics on heating and cooling loads. Applied Energy, 2006, 83(9), 989-1003

10. Chow T.T., He W. and Ji J. An experimental study of façade - integrated Photovoltaic/water heating system. Applied Thermal Engineering, 2007, 27, 37-45.

11. Chow T.T., Chan A.L.S., Fong, K.F., Lin, Z. and Ji J., Annual performance of building integrated photovoltaic water heat system for warm climate application. Applied Energy, 2009, 86, 689-696

12. Zogou O. and Stapountzis H., Energy analysis of an improved concept of integrated PV panels in an office building in central Greece. Applied Energy, 2011, 88, 853-866.

13. Fung, Y. Y. T. and Yang, H., Study on thermal performance of semi-transparent building-integrated photovoltaic glazings. Energy and building, 2008, 40, 341-350.

14. Lin Lu and Kin Man Law, Overall energy performance of semi-transparent singleglazed photovoltaic (PV) window for a typical office in Hong Kong, Renewable Energy, 2013, 49, 250-254.

15. Wu, Y., Connelly, K., Liu, Y., Gu, X., Gao, Y., and Chen, G. Z., Smart solar concentrators for building integrated photovoltaic façades, solar energy, 2016. 133: p.111-118.

16. Gladen, A.C., J.H. Davidson, and S.C. Mantell, Selection of thermotropic materials for overheat protection of polymer absorbers. Solar Energy, 2014. 104: p. 42-51.

17. Watanabe, H., Intelligent window using a hydrogel layer for energy efficiency. Solar Energy Materials and Solar Cells, 1998. 54(1-4): p. 203-211.

18. Nitta, Y. and K. Nishinari, Gelation and gel properties of polysaccharides gellan gum and tamarind xyloglucan. Journal of Biolological Macromolecules, 2005. 5(3): p. 4752.

19. Ferris, C.J., et al., Modified gellan gum hydrogels for tissue engineering applications. Soft Matter, 2013. 9(14): p. 3705-3711.

20. McClements, D.J., Nanoparticle- and Microparticle-based Delivery Systems: Encapsulation, Protection and Release of Active Compounds. 2014: CRC Press.

21. Aguilera, J.M., et al., Food Engineering Interfaces. 2010: Springer New York.

22. Elmowafy, E.M., et al., Release mechanisms behind polysaccharides-based famotidine controlled release matrix tablets. AAPS PharmSciTech, 2008. 9(4): p. 1230-1239.

23. Schneider, J. and A. Seeboth, Natural thermotropic materials for solar switching glazing. Materialwissenschaft und Werkstofftechnik, 2001. 32(3): p. 231-237.

24. Mori, T., et al., Alternative approach to the design of thermosensitive polymers: The addition of hydrophobic groups to the ends of hydrophilic polyether. Journal of Polymer Science, Part A: Polymer Chemistry, 2005. 43(5): p. 1007-1013.

25. Urry, D.W., Physical chemistry of biological free energy transduction as demonstrated by elastic protein-based polymers. Journal of Physical Chemistry B, 1997. 101(51): p. 11007-11028.

26. BSI, Glass in building - Determination of luminous and solar characteristics of glazing, in Determination of characteristics. 2011.

27. Young Tae Chae, Jeehwan Kim, Hongsik Park, Byungha Shin, Building energy performance evaluation of buildnig integrated photovoltaic window with semitransparent solar cells. Applied Energy, 2014, 129, 217-227.

28. Firdaus Muhammad-Sukki, Siti Hawa Abu-Bakar, Roberto Ramirez-Iniguez, Scott G. McMeekin, Brian G. Stewart, Abu Bakar Munir, Siti Hajar Mohd Yasin, Ruzairi Abdul Rahim, Performance analysis of a mirro symmetrical dielectric totally 
internally reflecting concentraor for building integrated photovoltaic systems. Applied Energy, 2013, 111, p. 288-299.

29. Firdaus Muhammad-Sukki, Siti Hawa Abu-Bakar, Roberto Ramirez-Iniguez, Scott G. McMeekin, Brian G. Stewart, Nabin Sarmah, Tapas Kumar Mallick, Abu Bakar Munir, Siti Hajar Mohd Yasin, Ruzairi Abdul Rahim, Mirror symmetrical dielectric totally internally reflecting concentrator for building integrated photovoltaic systems.Applied Energy 2014, 113, 32-40.

30 Siti Hawa Abu-Bakar, Firdaus Muhammad-Sukki, Roberto Ramirez-Iniguez, Tapas Kumar Mallick, Abu Bakar Munir, Siti Hajar Mohd Yasin, Ruzairi Abdul Rahim, Rotationally asymmetrical compound parabolic concentrator for concentrating photovoltaic applications. Applied Energy, 2014, 136, 363-372.

31 Siti Hawa Abu-Bakar, Firdaus Muhammad-Sukki, Daria Freier, Roberto RamirezIniguez, Tapas Kumar Mallick, Abu Bakar Munir, Siti Hajar Mohd Yasin, Abdullahi Abubakar Mas'ud, Norhidayah Md Yunus, Performance analysis of a novel rotationally asymmetrical compound parabolic concentrator. Applied Energy, 2015, 154, 221-231.

32 M. Sabry, Yasser A. Abdel-Hadi, A. Ghitas, PV-integrated CPC for transparent façades. Energy and Building, 2013, 480-484.

33 Mohamed Sabry, Prismatic TIR (total internal reflection) low-concentration PVintegrated façade for low latidues. Energy, 2016, 107, 473-481.

34 A. Kerrouche, D.A. Hardy, D. Ross, B.S. Richards, Luminescent solar concentrators: From experimental validation of 3D ray-tracing simulations to coloured stained-glass windows for BIPV. Solar Energy Materials and Solar Cells, 2014, 122, 99-106.

35 Nazmi Sellami, Tapas K. Mallick, Optical characterisation and optimisation of a static Window Integrated Concentrating Photovoltaic system. Solar Energy, 91, 273-282.

36 Nabin Sarmah, Tapas K. Mallick, Design, fabrication and outdoor performance analysis of a low concentrating photovoltaic system. Solar Energy, 2015, 112, 263372.

37 Karim Menoufi, Daniel Chemisana, Joan I. Rosell, Life Cycle Assessment of a Building Integrated Concentrated Photovoltaic scheme. Applied Energy, 2013, 111, 505-514. 